\title{
Monitoring of atmospheric dust deposition by using a magnetic method
}

\author{
A. Kapička, E. Petrovský \& H. Grison \\ Institute of Geophysics ASCR, Czech Republic
}

\begin{abstract}
Several studies showed that atmospheric dust contains significant portions of minerals characterized by ferrimagnetic properties. These minerals, mostly iron oxides, can serve as tracers of industrial pollutants in soil layers. In our paper we have investigated magnetic properties of depth soil profiles from the Ore Mountains (Czech Republic), which belong to a highly contaminated, so-called Black Triangle in central Europe. Emissions are determined by considerable concentration of big sources of pollution (power plants burning fossil fuel, metallurgical and chemical industry). Increased values of magnetic susceptibility $\left(25-100 \times 10^{-5} \mathrm{SI}\right)$ were clearly identified in the top-soil layers. Thermomagnetic analyses and SEM observation indicate that the accumulated anthropogenic ferrimagnetics dominate these layers. Magnetic enhancement is limited to depths of 4-7 cm below the soil surface, usually in F-H or on the top of Ah soil horizons; deeper soil horizons contain mainly magnetically weak materials and are characterized by much lower values of susceptibility (up to $20 \times 10^{-5} \mathrm{SI}$ ). Significant magnetic parameters (e.g. Curie temperature $\mathrm{T}_{\mathrm{C}}$ ) and SEM results of contaminated topsoils are comparable with magnetic parameters of atmospheric dust, collected (using high-volume samplers) at the same localities.
\end{abstract}

Keywords: atmospheric dust, topsoil pollution, magnetic susceptibility.

\section{Introduction}

Results of regular monitoring provide information on the temporal development of air pollution and spatial distribution of the pollutants concentration over the territory of Czech Republic. Distribution of the pollutants is very complex and depends upon several factors. Emissions from local heating, traffic and partly 
medium sized sources are of local extent, while those from major sources can be transported over long distances, often even outside the country territory.

Dust particles are a significant threat to human health and, thus, represent major problem in air pollution. Industrial dust particles are emitted, among others, by combustion (of fossil fuel in stationary sources and fuel in traffic). About two thirds of PM10 and half of finer, more harmful PM2.5 fraction are produced by electric plants. Traffic is another significant source of these particles and, moreover, causes redistribution of already deposited particles back to the atmosphere.

Generally, two different approaches are used to measure the amount of dust deposited on a surface; Determination of the quantity of dust deposited in terms of weight, or determination of the soiling of a surface, by a change in its properties. The former approach uses high-volume samplers. This method determines average dust concentrations and comprises the collection of dust by drawing a constant flow rate of ambient air through a collector. Data are usually collected over a 24-hour period and results are expressed in mass of dust per unit volume of air per $24 \mathrm{hrs}$. A selective inlet may be fitted to a high-volume sampler to restrict the particle size being sampled (for example, to ensure only PM10 particles are sampled). Measurement of magnetic properties of contaminated soil surface exemplifies second approach for monitoring of air pollution.

Currently, ambient air pollution caused by suspended particles represents a major problem not only in the Czech Republic but almost throughout the whole of Europe. With regard to health risks, especially fine particles represent the most difficult challenge. Analyses of measured data show that the PM10 limit values are markedly exceeded in a number of sites throughout the country [3].

Contamination due to deposition of particulate matter shows significant variability within the Czech Republic. National parks, such as the Giant Mountains (NE Bohemia) and Sumava (SW Bohemia) belong to the cleanest areas. There are no major sources of atmospheric pollution in the surrounding area and relatively low concentrations of atmospheric dust are due to long-range transport. The average annual concentration of PM10 is in both the regions $<15$ $\mu \mathrm{g} / \mathrm{m}^{3}$, which is well below the allowance limit. On the other hand, the Ore Mountains region, which is part of the "black triangle" area [4], belongs to the most polluted parts of the Czech Republic. This area is on the junction between the Czech Republic, Germany and Poland and contains numerous sources of atmospheric pollution, such as major power plants burning high-sulphur brown coal, chemical industry, incinerators and big heat plants, intense automobile and rail traffic, deposits of power-plant ashes, waste dumps, deposits of overburdens, etc. The average annual concentration of PM10 $\left(35-46 \mu \mathrm{g} / \mathrm{m}^{3}\right)$ in the area of the Ore Mts. foredeep belongs to the highest within the Czech Republic. The situation on the top of the Ore Mts. is somewhat better, with an average annual concentration of PM10 at about $20 \mu \mathrm{g} / \mathrm{m}^{3}$ [3].

In this study, we demonstrate the application of a magnetic method to assess contamination of soils due to atmospheric deposition in the Ore Mountains region. Soil magnetometry has several advantages. It is fast and, contrary to 
stationary monitoring stations, allows data acquisition at a large number of sites, thus enabling better delineation of areas with different amounts of deposited dust. Areas with higher imissions can be thus targeted for sampling for more detailed and standardized chemical analyses.

\section{Magnetic study of soil contamination due to atmospheric dust deposition}

Deposited dust accumulates mostly in topsoils and sediments. However, in order to assess the contamination due to industrial activities, discrimination between anthropogenic and natural (weathering of geological basement, pedogenic processes, etc.) contributions is necessary. This can be achieved by analyzing the magnetic properties of contaminated samples collected in the areas of concern.

Magnetic susceptibility $(k)$ measured in a low magnetic field is one of the most important parameters used in environmental magnetism. In the case of soil samples, this integral parameter represents combined contributions of diamagnetic (iron-free silicates and carbonates), paramagnetic (silicates containing $\mathrm{Fe}$ and $\mathrm{Mn}$ ), antiferromagnetic (e.g. hematite) and ferrimagnetic (e.g. maghemite and magnetite) minerals. Magnetic susceptibility is composition and concentration dependent parameter and primarily can be considered to reflect concentration of (strongly magnetic) ferrimagnetic substances.

Interpretation of magnetic data depends on the samples examined. It is relatively easy and straightforward in the case of passive biomonitors, such as tree leaves, needles, or peat bogs, where atmospheric dust particles are deposited on (magnetically weak) diamagnetic substances (e.g. [5]). However, availability of these collectors is rather limited to certain localities. The other disadvantage is low concentration of the deposited material and, thus, the need for highlysensitive instruments, which are not available for the in-situ monitoring. Contrary to that, the soil surface represents the most obvious trap to atmospheric fallout. Consequently, topsoil measurements are often used in assessing the soil contamination due to atmospheric deposition of dust particles (e.g. [6]). Fig. 1 shows typical vertical distribution of magnetic susceptibility in forest soil from localities distributed evenly over the territory of the Ore Mountains, Czech Republic. Low-field magnetic susceptibility was measured on depth soil cores, using a Bartington MS2C sensor. A significant increase of magnetic susceptibility in the uppermost $(4-7 \mathrm{~cm})$, organic L-F and $\mathrm{Ah}$ horizons is commonly observed. In deeper soil layers, magnetic susceptibility is considerably less.

Relative contribution of ferrimagnets of natural origin in topsoils is mainly due to two factors: weathering of geological basement and neoformation of ferrimagnetic minerals during pedogenic processes. Mineral composition of underlying rocks is the primary factor influencing mineral populations in the developed soils. However, vertical distribution of magnetic susceptibility can easily identify sites with significant geological contribution to magnetic enhancement of topsoils [7]. The other contribution results from oxidationreduction processes in soils, transforming magnetically weak low-crystalline Fe- 


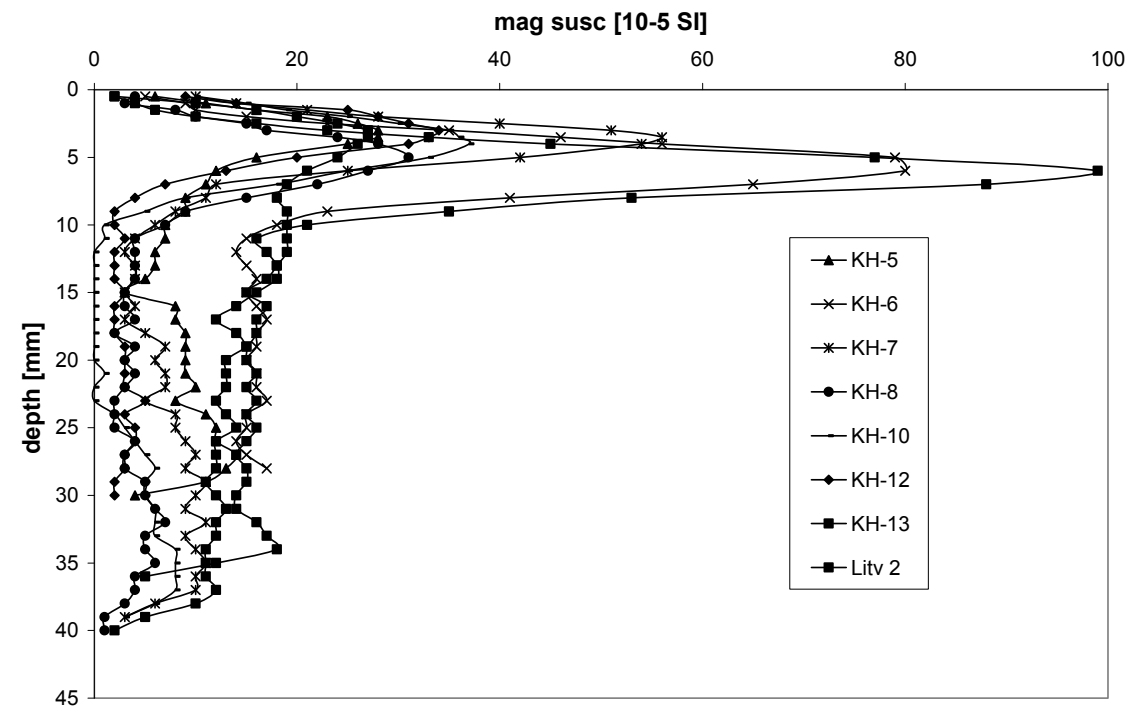

Figure 1: Typical depth soil profiles of magnetic susceptibility from Ore Mountains region in Czech Republic.

oxides and Fe-hydroxides to magnetically strong maghemite/magnetite. However, these particles of pedogenic origin are prevailingly in a form of very fine, superparamagnetic (SP) or single-domain (SD) grains and their relative significance can be estimated using frequency-dependent magnetic susceptibility $k_{\mathrm{FD}}[8]$.

Atmospheric dust of industrial origin contains Fe-oxides, magnetite $\left(\mathrm{Fe}_{3} \mathrm{O}_{4}\right)$, maghemite $\left(\gamma-\mathrm{Fe}_{2} \mathrm{O}_{3}\right)$ and hematite $\left(\alpha-\mathrm{Fe}_{2} \mathrm{O}_{3}\right)$. These are most often produced during combustion of fossil fuel (in, e.g., power plants) by decomposition of pyrite or Fe-rich clay minerals present in coal, followed by high-temperature oxidation of iron [2]. Also, emissions from industrial units such as steel and cement works, as well as traffic represent significant sources of anthropogenic ferrimagnets (e.g. [9-11]). Magnetic properties of industrially derived ferrimagnets are different from those of natural origin. In terms of morphology, they are typically of spherical shape, with Fe-oxides sintered on Al-Si phase. Their typical size varies between about 2 and $50 \mu \mathrm{m}$ and from magnetic point of view multi-domain (MD) structures prevail [12].

\section{Results and discussion}

Increased concentration of atmospherically deposited ferrimagnetics of anthropogenic origin was found in the topsoil layers. However, we still have to prove the presence of ferrimagnetics in the collected PM10 samples and to show that this substance has magnetic properties similar to those of the topsoil layer.

Therefore, thermomagnetic analyses (temperature dependence of magnetic susceptibility) were carried out using KLY-4S Kappabridge equipped with CS-3 
furnace (AGICO, Brno, Czech Republic). Both samples of quartz microfiber filters with PM10 and magnetic extracts of soil samples were measured at temperatures from 20 to $700^{\circ} \mathrm{C}$ in order to detect temperatures of magnetic phase transitions of major ferrimagnetic minerals. Samples of the L-F soil horizons were dominated by magnetite with Curie temperature of about $580^{\circ} \mathrm{C}$ (Fig. 2). Magnetic composition of bottom soil layers is always more complex, showing a whole sequence of transformations of magnetically weak minerals at elevated temperatures. In the case of PM10 samples, despite very minute concentration, magnetite could be identified as well. This finding is of crucial importance for justification of magnetic monitoring of atmospherically deposited dust using soil magnetometry in the region of the Ore Mountains.

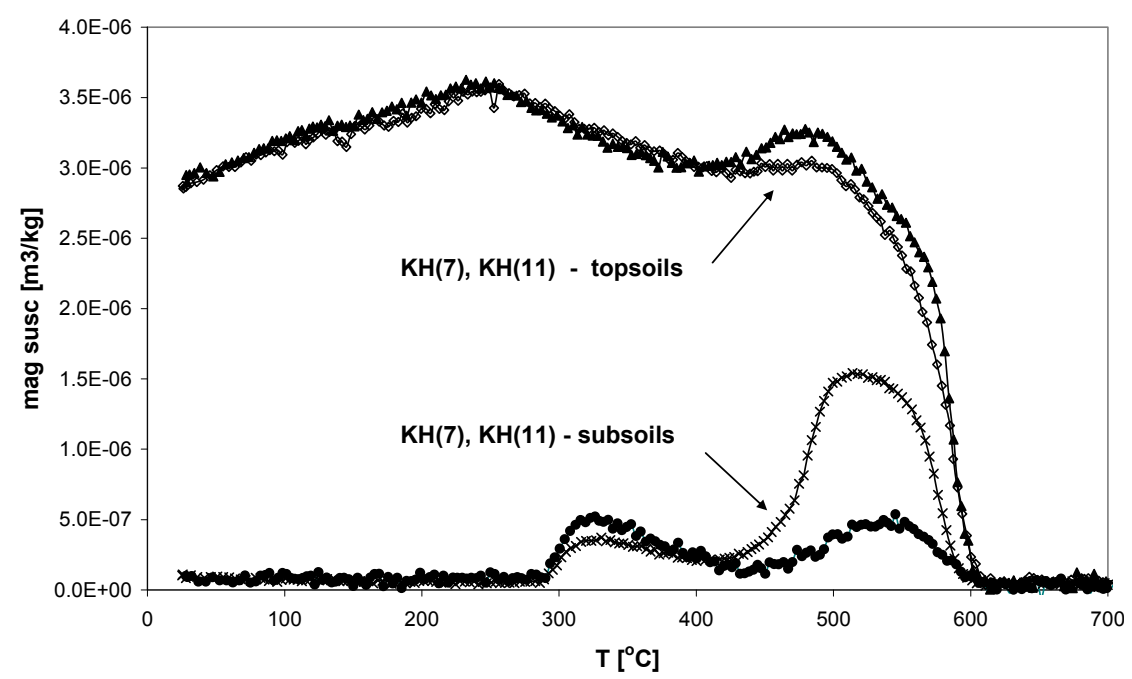

Figure 2: $\quad$ Temperature dependence of magnetic susceptibility for topsoil and subsoil samples from different localities in the Ore Mts.

Anthropogenic ferrimagnetic particles in atmospheric dust have typical morphology. Those resulting from combustion processes are typically spherules with the size from 5 to about $50 \mu \mathrm{m}$ (e.g. [12]). We examined using SEM magnetic extract of the topsoil samples the as well as PM10 samples. Typical result is depicted in Fig. 3. Spherical Fe-rich particles, with variable grain size, were found in magnetic extracts of topsoil samples. Despite the fact that the PM10 samples contain only smaller particles, below $10 \mu \mathrm{m}$, similar particles were also identified. Deeper mineral soil horizons were free of these Fe-rich spherules, which are presumably of industrial origin.

Monitoring of PM10 is performed using stationary high-volume samplers located at the Ore Mountains piedmont at the altitude of $300 \mathrm{~m}$ a.s.l. (Lom) and close to the summit (Rudolice, $780 \mathrm{~m}$ a.s.1.). On both sites, sampling is during $24 \mathrm{hrs}$ and the air flow through the sampler is about $720 \mathrm{~m}^{3} /$ day. Long-term monitoring clearly showed that the highest concentrations of atmospheric dust in 
Table 1: PM10 concentrations in sampler filters from two localities in the Ore Mts.

\begin{tabular}{|l|c|c|c|c|}
\hline \multicolumn{1}{|c|}{ Locality } & Date & $\begin{array}{c}\text { Conc. } \\
{\left[\mu \mathrm{g}^{-3}\right]}\end{array}$ & Date & $\begin{array}{c}\text { Conc. } \\
{\left[\mu \mathrm{m}^{-3}\right]}\end{array}$ \\
\hline Rudolice $(780 \mathrm{~m})$ & Oct. 24, 2008 & $\begin{array}{l}17 \\
68\end{array}$ & Jan.13, 2009 & $\begin{array}{c}29 \\
138\end{array}$ \\
Lom (300 m) & Oct. 25, 2008 & 23 & Jan.15, 2009 & $\begin{array}{c}8 \\
225\end{array}$ \\
\hline Rudolice (780 m) & & 67 & & 17 \\
Lom (300 m) & Oct. 26, 2008 & 17 & Jan.17, 2009 & 92 \\
\hline Rudolice (780 m) & & 47 & & \\
Lom (300 m) & & &
\end{tabular}

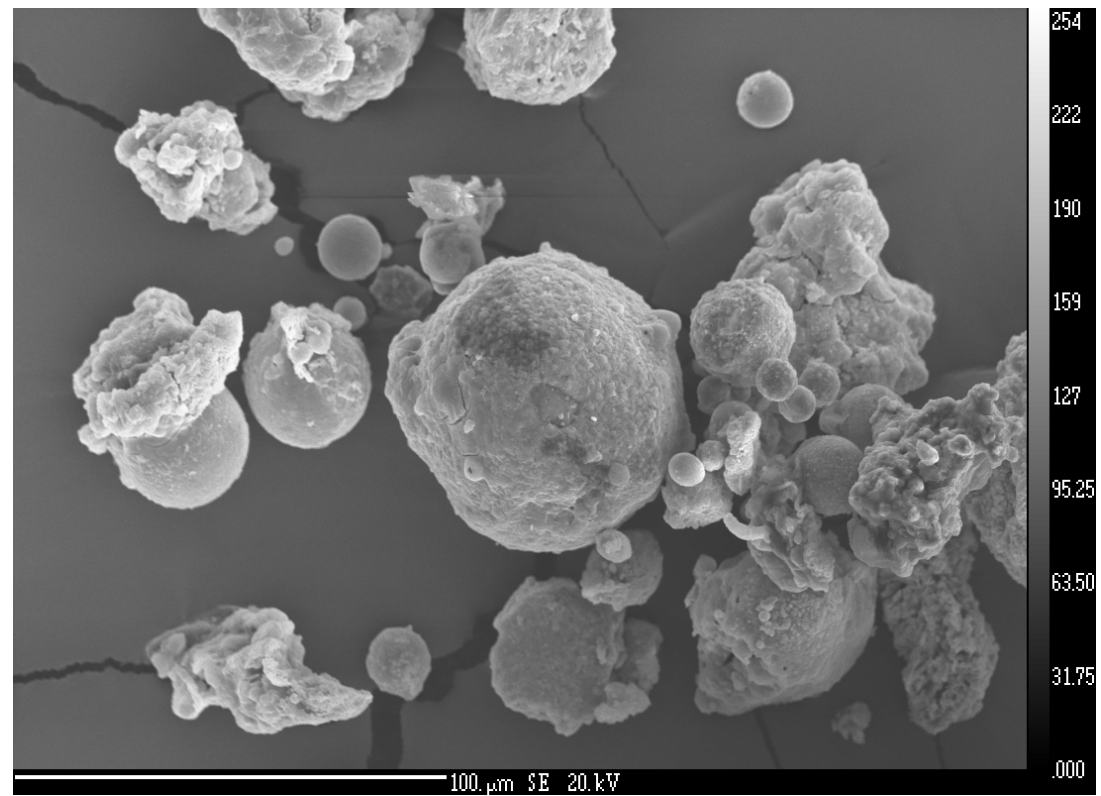

Figure 3: $\quad$ SEM of ferrimagnetic spherules in topsoil magnetic extract.

this region are in the winter period [3]. Therefore, for demonstration of PM10 concentration variations with different altitude, typical values obtained in October 2008 and January 2009 were used. PM10 concentration sampled on 24, 25, 26 October 2008 and 13, 15, 17 January 2009 in both the localities are listed in Table 1. High concentrations in the piedmont are attributed to major sources of air pollution in the close neighbourhood (power plants, smelters). Comparison with the summit concentrations suggests limited transport of PM10 to higher altitudes. 


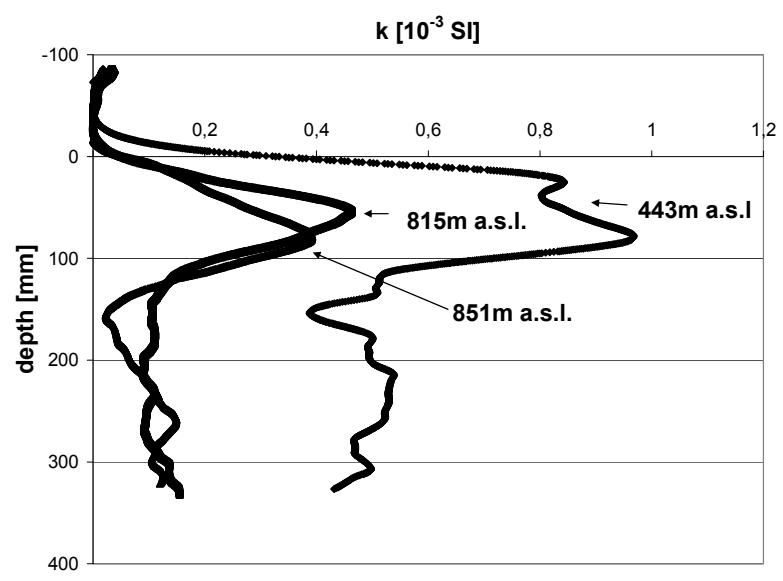

Figure 4: Depth soil profiles of magnetic susceptibility at sites with different altitude (443 m, $815 \mathrm{~m}$ and $851 \mathrm{~m}$ a.s.l) in the Ore Mts.

Vertical distribution of magnetic susceptibility was measured to depths of $30-40 \mathrm{~cm}$ on forest soils along the whole altitude profile from piedmont to the summit using MAGPROX SM400 kappameter (ZHInstruments, Brno, Czech Republic [13]). Profiles were measured in the altitudes of $443 \mathrm{~m}, 815 \mathrm{~m}$ and $851 \mathrm{~m}$ a.s.1. In all the cases the profiles show clearly magnetically enhanced superficial (L-F) pedozones (Fig. 4). At the same time, magnetic susceptibility in deeper mineral horizons is much lower and practically constant. This pattern suggests dominance of atmospherically deposited anthropogenic ferrimagnetics and the negligible effect of natural minerals of lithogenic origin (e.g. [14]). The maximum value of magnetic susceptibility along the depth profiles seems to depend upon the altitude, the higher the altitude, the lower magnetic enhancement in the topsoil layer. This finding reflects qualitatively the differences in PM10 concentrations in the piedmont and summit sites.

\section{Conclusions}

Our results prove that measurements of topsoil magnetic susceptibility can help in assessing the spatial distribution of soil contamination due to atmospheric deposition of pollutants over the area of the Ore Mts. Topsoil horizons are magnetically enhanced due to the presence of a magnetic mineral phase which shows similar characteristics as that found in the collected PM10 samples, and which is presumably of industrial origin. Magnetic susceptibility of the enhanced topsoil layer shows qualitatively similar altitude dependence as concentration of atmospheric PM10. If certain rules are obeyed (estimating the significance of ferrimagnetic particles of lithogenic and/or pedogenic origin), a magnetic method can be used for relatively fast and cheap assessment of soil contamination due to atmospheric deposition of pollutants. Contrary to routinely used stationary PM10 
samplers, soil magnetometry allows acquisition of large datasets, covering the area in concern with much larger density. Hence, it allows delineation of significantly contaminated areas for more targeted sampling for detailed chemical analyses, which are more expensive and time consuming. However, soil magnetometry can only be considered as a proxy and approximate method, which is site specific and has to be always calibrated using available environmental data.

\section{Acknowledgements}

This study was supported by the Grant Agency of the Czech Republic through grant No. 205/07/0941 and the Grant Agency ASCR through project No. IAA300120701

\section{References}

[1] Kapička, A., Jordanova, N., Petrovský, E. \& Ustjak, S., Magnetic stability of power-plant fly-ashes in different soil solutions. Phys. Chem. Earth (A), 25(5), pp. 431-436, 2000.

[2] Flanders, P.J., Collection, measurements and analysis of airborne magnetic particulates from pollution in the environment. J. Appl. Phys., 75, pp. 59315936, 1994.

[3] Statistical environmental yearbook of the Czech Republic 2006. Ministry of the Environment of the Czech Republic (MZP CR), Praha, 2007.

[4] Hykyšová, S. \& Brejcha, J., Monitoring of PM10 air pollution in small settlements close to opencast mines in the North-Bohemian Brown Coal Basin. WIT Transactions on Ecology and the Environment, 123, pp. 387398, 2009.

[5] Zhang, C.X., Huang, B.C., Piper, J.D.A. \& Luo, R.S., Biomonitoring of atmospheric particulate matter using magnetic properties of Salix matsudana tree ring cores. Sci. Tot. Environ., 393, pp. 177-190, 2008.

[6] Petrovský, E., Kapička, A., Jordanova, N., Knab, M. \& Hoffmann, V., Magnetic susceptibility - a proxy method of estimating increased pollution of different environmental systems. Environ. Geol., 39(3-4), pp. 312-318, 2000.

[7] Kapička, A., Jordanova, N., Petrovský, E. \& Podrázský, V., Magnetic study of weakly contaminated forest soils. Water Air Soil Pollut., 148(1-4), pp. 31-44, 2003.

[8] Maher, B.A. \& Taylor, R.M., Formation of ultrafine-grained magnetite in soils. Nature, 336, pp. 368-370, 1988.

[9] Zheng, Y. \& Zhang, S.H., Magnetic properties of street dust and topsoil in Beijing and its environmental implications. Chinese Sci. Bull., 53, pp. 408417, 2008.

[10] Hoffmann, V., Knab, M. \& Appel, E., Magnetic susceptibility mapping of roadside pollution. J. Geochem. Explor., 66, pp. 313-326, 1999. 
[11] Kim, W., Doh, S.J., Park, Y.H. \& Yun, S.T., Two-year magnetic monitoring in conjunction with geochemical and electron microscopic data of roadside dust in Seoul, Korea. Atmos. Environ., 41, 7627-7641, 2007.

[12] Strzyszcz, Z., Magiera, T. \& Heller, F., The influence of industrial immisions on the magnetic susceptibility of soils in Upper Silesia. Stud. Geophys. Geod., 40, pp. 276-286, 1996.

[13] Petrovský, E., Hůlka, Z. \& Kapička, A., A new tool for in situ measurements of the vertical distribution of magnetic susceptibility in soils as basis for mapping deposited dust. Environ. Technol., 25, pp. 1021-1029, 2004.

[14] Magiera, T., Strzyszcz, Z., Kapička, A., Petrovský, E. \& MAGPROX Team, Discrimination of lithogenic and anthropogenic influences on topsoil magnetic susceptibility in Central Europe. Geoderma, 130, pp. 299-311, 2006. 